\title{
More than the sum of the parts: cooperation between leukocyte adhesion receptors during extravasation
}

\section{Commentary}

See related article, Volume 106,

N umber 12, pages 1457- 1466.

\author{
Mark Siegelman
}

Department of Pathology, N B6.412, University of Texas Southwestern M edical Center, $6000 \mathrm{H}$ arry Hines Boulevard, Dallas, Texas 75390-9072, USA. Phone: (214) 648-4121; Fax: (214) 648-4070; E-mail: siegelman@utsw.swmed.edu.

Over the past decade, it has become clear that the specificity and targeted regulation of leukocyte trafficking result from the sequential and frequently overlapping functions of various adhesive receptors. Adhesion between the leukocyte and the vessel wall begins with repeated transient interactions that allow the leukocyteto "roll" across the endothelium at a rate lower than that of blood flow. Rolling is attributed to the interaction between carbohydrate ligands and either members of the selectin family $(1,2)$ or $\operatorname{CD} 44(3,4)$ and is followed by firm adhesion mediated by receptors of a different class, the leukocyte integrins. These integrins require activationinduced avidity increases to bind their ligands, generally members of the immunoglobulin genesuperfamily.

The primary relevant integrins expressed by leukocytes contain either $\alpha_{4}$ (the heterodimers $\alpha_{4} \beta_{1}$ and $\alpha_{4} \beta_{7}$ ) or $\beta_{2}$, also known as CD 18, which heterodimerizes with any of four distinct $\alpha$ chains to form LFA-1, M ac-1, p150,95, and $\alpha_{d} \beta_{2}(5)$. The combination of adhesion receptor expression and microenvironmental influences encountered by leukocytes as they traversetheendothe lium controls integrin activation and determines the leukocyte subsets recruited to a particular site and the kinetics with which this recruitment occurs. Loss of any of the adhesion molecules in this scheme could result in reduced extravasation of particular leukocyte subsets at sites of inflammation. Early studies of leukocyte adhesion molecule deficiency 1 disease (LADI), a genetic deficiency in which affected patients are subject to recurrent bacterial and fungal infections and have impaired wound healing, showed mutations in CD 18. It is perhapsfitting that the manuscript by Forlow et al. in a recent issue of the $\mathrm{Jl}$ (6) focuses in part on the same molecule.

M ice lacking all three selectins, the $\beta_{2}$ integrins, ICAM -1, or various combinations of these adhesion receptors have been generated with varying outcomes in induced inflammatory models, but generally these strains remain healthy under standard laboratory conditions $(7,8)$. The earliest indication of a spontaneous inflammatory defect resulting from adhesion receptor genetargeting was seen in mice doubly deficient for $\mathrm{E}$ and P-selectin. Similar to the phenotype reported in the present study, theabnormalities in these mice consist primarily of excoriative skin lesions associated with bacterial colonization in the head and neck $(9,10)$. Rolling interactions are severely compromised in E/Pselectin-deficient mice, which fail to inducenormal inflammatory responses to peritoneal infection with Streptococcus pneumoniae. These studies clearly established rolling as a prerequisite for firm adhesion. The second instance of a spontaneous and severe inflammatory condition was identified in CD 18-deficient mice, again consisting primarily of mucocutaneous lesions (11). N early all mice of this genotype devel op a similar progressiveulcerative dermatitis and are highly susceptibleto inoculated S. pneumoniae. Intravital microscopy revealed that firm adhesion but not rolling is markedly impaired in thesemice.

\section{Rethinking the stages of leukocyte adhesion}

The primary impetus for the current study by Forlow et al. (6) was theobservation that leukocyte rolling velocities are markedly increased in CD 18-deficient mice, suggesting a previously unsuspected role for $\beta_{2}$ integrins in mediating theinitial phase of adhesion. The addition of anti-E-selectin antibody further increases rolling velocities and markedly decreases leukocyte stable adherence and recruitment. These findings reinforce the view that rolling velocity regulates the efficiency of leukocyterecruitment into infected tis- sues (12), but they hint at an unexpected collaboration between two receptors thought to participate in independent stages of this process. In view of the present data and those in several other studies (13-15), the paradigm of separate sequential steps of leukocyte extravasation may have to yield to an alternativemodel involving overlapping and collaborative roles for the various adhesive receptors.

Still more surprising is the markedly reduced viability of the E-selectin/CD 18 doublemutant miceand the severity of their phenotype. M utant animals fail to thrive and are severely runted. Animals surviving to 6 weeks of age develop mucocutaneous skin lesions morphologically similar to those of E/P-selectin double and CD18 single mutants (9-11). Because of the animals' abbreviated lifespan, Forlow et al. recreated the double-mutant system in adults, conducting their intravital microscopy studies in E-selectin mutant mice reconstituted with bonemarrow from $\mathrm{CD} 18$ mutant mice (6). Even so, fully one-half of animals did not survive appreciably beyond transplantation. The survivors were unhealthy and recapitulated the chroniculcerative dermatitis seen in the original double mutants. The specificity of this severe phenotype is all the more remarkable considering that $\mathrm{P}$ selectin/CD 18-null mice are indistinguishable grossly from wild-type, survive to adulthood, and breed successfully. Why the sel ective cooperation between CD 18 and E- but not Pselectin? Since E-selectin is generally considered more important in slow rolling, this phenotypic difference may point to a juncture, perhaps immediate ly prior to the commitment to firm adhesion, at which E-selectin is unique ly required. Such an E-selectin-dependent step may represent an essential transition phase in extravasation, indeed one more critical than that established by endothelial selectin knockouts. 
The extreme impact on viability is remarkableand unexplained. Heterozygous matings result in expected mendelian ratios of offspring, suggesting no gross in utero developmental problems (6). Hematopoietic abnormalities and splenomegaly do not appear markedly different from some other adhesion molecule-deficient animals and are therefore unlikely to account for the early lethality. Themost likely candidatein this respect would be infectious. Bacterial cultures of blood and other tissues were negative, but a potential viral or fungal etiology was not excluded; nor was a metabolic derangement addressed (6).

Could there be another vital requirement for a constitutive basal level of leukocyte infiltration into tissues? Thereis no precedent for such an explanation, but then no gene deficiency before has resulted in such a profound leukocyte infiltration defect. Still, this defect is not absolute, sinceForlow et al. noted a mild lymphocytic and neutrophilic infiltratein skin lesions in the double mutants (6). Moreover, although bacterial pneumonia was not evident, the animals show an increased neutrophilic infiltration in the lung, suggesting that alternative adhesive pathways operatein this organ $(16,17)$. Although the unique severity of the phenotype is clear, other comparisons to prior knockouts are more difficult. Common models of induced cuta- neous, lung, or peritoneal inflammation have yet to be evaluated and may be informative in further defining the nature and extent of the inflammatory defect, and perhaps in providing insight into early mortality. N onetheless, the study (6) clearly indicates that the various adhesion receptors contribute in a continuous manner to extravasation. In particular, it suggests that collaboration between these two adhesion receptors is essential, not compensated by other mechanisms, and defines a unique and critical juncture in the adhesion cascade.

1. Von Andrian, U.H., et al. 1991. Two-step model of leukocyte-endothelial cell interaction in inflammation: distinct roles for LECAM - 1 and the leukocyte beta 2 integrins in vivo. Proc. Natl. Acad. Sci. USA. 88:7538-7542

2. Springer, T.A. 1994. Traffic signals for lymphocyte recirculation and leukocyte emigration: the multistep paradigm. Cell. 76:301-314.

3. DeGrendele, H.D., Estess, P., and Siegelman, M.H. 1997. Requirement for CD 44 in activated $\mathrm{T}$ cell extravasation into an inflamed site. Science. 278:672-675.

4. DeGrendele, H.C., Estess, P., Picker, L.)., and Siegelman, M.H. 1996. CD 44 and its ligand hyaluronate mediate rolling under physiologic flow: a novel lymphocyte/endothelial cell primary adhesion pathway. J. Exp. Med. 183:1119-1130.

5. Anderson, D.C., and Springer, T.A. 1987. Leukocyte adhesion deficiency: an inherited defect in the M ac-1, LFA-1, and p150,95 glycoproteins. Annu. Rev. M ed. 38:175-194.

6. Forlow, S.B., et al. 2000. Severe inflammatory defect and reduced viability in CD 18 and Eselectin double-mutant mice. J. Clin. Invest. 106:1457-1466.

7. Kansas, G.S. 1996. Selectins and their ligands: current concepts and controversies. Blood.
88:3259-3287

8. Etzioni, A., D oerschuk, C.M ., and Harlan, J.M. 1999. Of man and mouse: leukocyte and endothelial adhesion molecule deficiencies Blood. 94:3281-3288.

9. Frenette, P.S., Mayadas, T.N., Rayburn, H., Hynes, R.O., and Wagner, D.D. 1996. Susceptibility to infection and altered hematopoiesis in mice deficient in both P- and E-selectins. Cell. 84:563-574.

10. Bullard, D.C., et al. 1996. Infectious susceptibility and severe deficiency of leukocyte rolling and recruitment in E-selectin and P-selectin double mutant mice. J. Exp. M ed. 183:2329-2336.

11. Scharffetter-Kochanek, K., et al. 1998. Spontaneous skin ulceration and defective $T$ cell function in CD18 null mice. J. Exp. Med. 188:119-131.

12. Jung, U., N orman, K.E., Scharffetter-Kochanek, K., Beaudet, A.L., and Ley, K. 1998. Transit time of leukocytes rolling through venules controls cytokine-induced inflammatory cell recruitment in vivo. J. Clin. Invest. 102:1526-1533.

13. Bargatze, R.F., Jutila, M.A., and Butcher, E.C. 1995. Distinct roles of $L$-selectin and integrins alpha 4 beta 7 and LFA-1 in lymphocytehoming to Peyer's patch-HEV in situ: the multistep model confirmed and refined. Immunity. 3:99-108.

14. Kunkel, E.J., et al. 1996. Absence of traumainduced leukocyte rolling in mice deficient in both P-selectin and intercellular adhesion molecule 1. J. Exp. M ed. 183:57-65.

15. Steeber, D .A., Campbell, M .A., Basit, A., Ley, K. and Tedder, T.F. 1998. Optimal selectin-mediated rolling of leukocytes during inflammation in vivo requires intercellular adhesion molecule-1 expression. Proc. Natl. Acad. Sci. USA 95:7562-7567.

16. D oerschuk, C.M., Winn, R.K., Coxson, H.O., and Harlan, J.M. 1990. CD 18-dependent and -inde pendent mechanisms of neutrophil emigration in the pulmonary and systemic microcirculation of rabbits. J. I mmunol. 144:2327-2333.

17. Mizgerd, J.P., et al. 1997. N eutrophil emigration in the skin, lungs, and peritoneum: different requirements for $C D 11 / C D 18$ revealed by CD18-deficient mice. J. Exp. Med. 186:1357-1364. 